\title{
DEGRADAÇÃO RUMINAL DOS TECIDOS VEGETAIS E COMPOSIÇÃO BROMATOLÓGICA DE CULTIVARES DE Axonopus scoparius (FLÜEGGE) KUHLM. E Axonopus fissifolius (RADDI) KUHLM ${ }^{1}$
}

\section{RUMINAL TISSUE DEGRADATION AND BROMATOLOGICAL COMPOSITION IN Axonopus scoparius (FLÜEGGE) KUHLM. E Axonopus fissifolius (RADDI) KUHLM CULTIVARS}

\author{
Lenir Maristela Silva Lima ${ }^{2}$ Yedo Alquini $^{3}$ Cláudio José Freixeiro Alves de Brito ${ }^{4}$ \\ Francisco Carlos Deschamps ${ }^{5}$
}

RESUMO

$O$ objetivo do presente trabalho foi determinar a composição química e a digestibilidade das folhas (lâminas $e$ bainhas) e caules de cultivares das espécies Axonopus scoparius e Axonopus fissifolius, em dois estádios de desenvolvimento. $O$ delineamento experimental foi inteiramente casualizado com dois tratamentos (seis e vinte semanas de crescimento) e cinco repetições. Para determinação da cinética de digestão, utilizou-se a técnica do saco de nylon, e a composição bromatológica foi determinada através da técnica do infra-vermelho (NIRS). A degradação dos tecidos foi observada histologicamente após a incubação de pequenas porções de caule e folhas em líquido ruminal de bovinos. Observou-se que, com a maturidade, os cultivares de A. scoparius apresentaram maior queda na taxa de degradabilidade efetiva, a qual foi relacionada com o espessamento da parede celular e aumento da área de tecido lignificado. O teor de proteína bruta foi o parâmetro mais afetado com o envelhecimento das espécies. A maior área de tecidos lignificados, encontrada nas frações foliares (limbo, quilha $e$ bainha) de $\boldsymbol{A}$. fissifolius, resultou em menores taxas de digestibilidade para os cultivares dessa espécie, em relação aos de A. scoparius. O cultivar "verde" de A. scoparius apresentou maior suscetibilidade à degradação ruminal, quando jovem, comparado ao cultivar "roxo", enquanto os de A. fissifolius apresentaram características similares ante à degradação ruminal. $O$ caule foi a fração cuja degradação decresceu em maior proporção quando comparado às frações foliares.

Palavras-chave: digestibilidade, FDN, forrageiras, lignina, NIRS, ruminantes.

\section{SUMMARY}

The present study aimed at determining the chemical composition and digestibility of leaves (sheath+blade) and stems belonging to Axonopus scoparius and Axonopus fissifolius cultivars, during two growing stages. A completely randomized design with two treatments ( 6 and 20 weeks of growing) and five replicates were used. The nylon bag technique was used to determine the digestion kinetics and the Near Infra Red Spectroscopy (NIRS) technique to determine the bromatological composition. Tissue degradation was histologically observed after the incubation of small stem and leaf portions in cattle ruminal liquid. With mature age, it was observed that Axonopus scoparius cultivars reduced the effective degradability, which was related to cell wall thickening and increased lignified tissue area. The level of crude protein was the parameter mostly affected as species grew older. Leaf fractions (limbo, keel and sheath) of Axonopus fissifolius showed large areas of lignified tissues, resulting in lower digestibility rates as compared to Axonopus scoparius. The Axonopus scoparius "verde" cultivar, proved more susceptible to ruminal digestion than "roxo" cultivar, whereas no differences were observed in Axonopus fissifolius cultivars. The stem was the part of plant presenting greater reduction in digestion as compared to the leaf portion.

Key words: digestibility, forage, lignin, NDF, NIRS, ruminants.

\section{INTRODUÇÃO}

As espécies Axonopus scoparius (Flügge) Kuhlm. (capim-imperial) e Axonopus fissifolius

\footnotetext{
${ }^{1}$ Parte da dissertação de Mestrado apresentada pelo primeiro autor ao Curso de Pós-graduação em Botânica da Universidade Federal do Paraná (UFPr).

${ }^{2}$ Biólogo, Mestre em Botânica, Professor Assistente, CEFET/PR - UNED/PB. Rodovia PR 469, km 1, 85.503-390, Pato Branco, PR.

${ }^{3}$ Biólogo, Doutor, Professor Adjunto, Departamento de Botânica, UFPR. Curitiba, PR.

${ }^{4}$ Engenheiro Agrônomo, Mestre em Botânica, Professor Adjunto, UniAndrade, Curitiba, PR.

${ }^{5}$ Médico Veterinário, Doutor, Pesquisador, EPAGRI S.A./UNIVALI, CP 277, 88301-970, Itajaí, SC, Brasil. E-mail: xicodsc@ hotmail.com. Autor para correspondência.
} 
(Raddi) Kuhlm. (grama missioneira) são gramíneas tropicais utilizadas na alimentação de bovinos, principalmente nas regiões do Vale do Itajaí e Litoral Norte do Estado de Santa Catarina.

A digestibilidade de uma forrageira está intimamente associada ao arranjo dos tecidos e sua composição bromatológica (HANNA et al., 1973; NASCIMENTO JUNIOR, 1974). Assim, é possível relacionar o potencial de digestibilidade da planta pela caracterização dos diferentes tecidos vegetais presentes nas várias frações das forrageiras (AKIN et $\boldsymbol{a l}$., 1983). De modo geral, observa-se que a presença de maiores quantidades de tecidos vasculares lignificados ou esclerenquimáticos proporcionam menores taxas de digestibilidade (WILKINS, 1972; WILSON, 1993; VENTRELLA, 1995; VENTRELLA et al., 1997; VENTRELLA et al., 1997b) ou redução na área degradada por microorganismos ruminais (WILSON, 1993; WILSON, 1997; ALVES DE BRITO et al., 1997; ALVES DE BRITO et al., 1999). WILKINS (1969) observou que alguns tecidos permanecem intactos, mesmo após prolongado tempo de digestão in vitro, indicando que as características anatômicas da planta limitam a degradação dos tecidos vegetais.

Alguns eventos são comumente observados com o envelhecimento do vegetal. Entre eles, destacam-se o espessamento e lignificação das paredes celulares, os quais implicam redução das áreas de digestão dos tecidos (AKIN et al., 1983; AKIN, 1989; HANNA et al., 1973), no aumento nos teores de fibra em detergente neutro (FDN) (HANNA $\boldsymbol{e} \boldsymbol{t} \boldsymbol{a l} .$, 1976) e fibra em detergente ácido (FDA) e decréscimo da porcentagem de proteína bruta (PB) (AKIN et al., 1977).

Os objetivos deste trabalho foram avaliar a degradação dos tecidos vegetais após degradação ruminal por $48 \mathrm{~h}$, determinar a composição bromatológica e a cinética da digestão ruminal de cultivares de Axonopus scoparius e Axonopus fissifolius, em dois estádios de desenvolvimento do vegetal.

\section{MATERIAL E MÉTODOS}

Os cultivares "roxo" e "verde" de cada uma das espécies encontravam-se estabelecidos em parcelas homogêneas de 10 x $25 \mathrm{~m}$ na Estação Experimental de Itajaí- EPAGRI S/A, em Itajaí-SC (265'ㄹ's, 48³9'43”'W, 5m.s.m.). O solo (Gley, pouco húmico, distrófico), apresentava inicialmente $\mathrm{pH}(\mathrm{smp})=5,2 \mathrm{e}$ teores de $\mathrm{P}=2,2 \mathrm{ppm}$ e $\mathrm{K}=30,0 \mathrm{ppm}$. Primeiramente, foi realizado um corte de uniformização em 25/11/1996, quando as parcelas receberam adubação de cobertura com quantidades correspondentes a
$150 \mathrm{~kg} / \mathrm{ha}$ de $\mathrm{N}, 110 \mathrm{~kg} / \mathrm{ha}$ de $\mathrm{P}_{2} \mathrm{O}_{5}$ e $140 \mathrm{~kg} / \mathrm{ha}$ de $\mathrm{K}_{2} \mathrm{O}$. $\mathrm{O}$ delineamento experimental foi inteiramente casualizado com dois tratamentos (períodos de crescimento) e 5 repetições cada. $\mathrm{O}$ material botânico foi coletado em duas fases de crescimento, cujos cortes ocorreram em 06/01/1997 e 11/04/1997. De cada parcela, foram selecionadas aleatoriamente cinco áreas correspondendo a um quadro de $0,5 \times 0,5 \mathrm{~m}$.

As coletas seguiram os parâmetros descritos por ALVES DE BRITO et al. (1999). Na primeira coleta das lâminas e bainhas foliares, foram retiradas amostras da porção mediana da terceira lâmina foliar totalmente expandida e de sua respectiva bainha, contando-se a partir do ápice da planta. Na segunda coleta, as amostras foram retiradas da quinta lâmina foliar. Para caules, foram retiradas amostras da porção mediana do entrenó localizado imediatamente acima da inserção das folhas mencionadas. Do material amostrado, parte foi destinado à degradação, parte à determinação bromatológica e parte à cinética de digestão.

Para a observação da degradação dos tecidos pela biota ruminal, pequenas porções da lâmina, bainha e caule, medindo aproximadamente $1 \mathrm{~cm}$, foram submetidas à digestão ruminal (bovino), com o material sendo incubado por um período de 48 horas. As frações foram acondicionadas em um pequeno pedaço de tubo de silicone e envolto por um tecido de nylon que apresentava porosidade média de $45 \mu \mathrm{m}$. Esse conjunto foi acondicionado em um outro saco de nylon de tamanho $15 \times 17 \mathrm{~cm}$, preso a uma haste plástica, sustentada por um fio de nylon de aproximadamente $50 \mathrm{~cm}$, preso na borda da fístula ruminal. Essa forma de proteção foi utilizada para evitar que a pressão exercida pelos movimentos ruminais fragmentasse as amostras. Ao final do tempo de incubação, o material foi removido, fixado em F.A.A. $70 \%$ (Formol:Ácido acético:Etanol 70\% - 5:5:90), por aproximadamente $48 \mathrm{~h}$, sendo posteriormente conservado em etanol $70 \%$ até o processamento final (JOHANSEN, 1940). Para a confecção do laminário, as amostras foram emblocadas em glicol metacrilato (GMA) JB4 (Polysciences, Inc.) de acordo com as especificações do fabricante e de FELDER \& O'BRIEN (1968). O seccionamento foi realizado em micrótomo rotatório Spencer 820, com espessura de 5 a $8 \mu \mathrm{m}$ e as secções coradas com Azul de Toluidina diluído em tampão acetato (pH 4,0).

As amostras destinadas à análise bromatológica foram secas em estufa de ar forçado a $55^{\circ} \mathrm{C}$ por 72 horas e moídas em moinho tipo Willey com peneira $2 \mathrm{~mm}$. Proteína bruta $(\mathrm{PB})$ e fibra em detergente ácido (FDA) foram analisadas, usando-se a técnica do infra-

Ciência Rural, v. 31, n. 3, 2001. 
vermelho (NIRS - Near Infra Red Spectroscopy), no Laboratório de Nutrição Animal do Departamento de Zootecnia, da Universidade Federal do Paraná, utilizando-se duas repetições de cada cultivar em cada época de coleta. Fibra em detergente neutro (FDN) foi determinada submetendo-se a amostra à digestão em solução detergente neutro por 40 minutos em autoclave $\left(120{ }^{\circ} \mathrm{C}\right)$. A lignina determinada no presente trabalho foi a denominada de lignina de Klason, a qual contém, além da lignina, alguns elementos minerais e sílica. Para essa determinação, as amostras, em triplicata, são submetidas à pré-hidrólise em ácido sulfúrico 12M durante 1 hora. Em seguida, o ácido é diluído para $0,4 \mathrm{M}$ e o material submetido à nova hidrólise em autoclave de bancada, por 60 minutos a $120^{\circ} \mathrm{C}$.

Para acompanhar a cinética de desaparecimento da matéria seca, foi utilizado o método do saco de nylon (ORSKOV \& McDONALD, 1979; NOCEK, 1988), com tempos de incubação ruminal de 0, 6, 24, 72 horas. As amostras, constituídas pela mistura das frações foliares e do caule, foram incubadas em duplicata para cada tempo, com o procedimento se repetindo para os três animais, ao mesmo tempo. Após o período de incubação, as amostras foram lavadas em água corrente e secadas em estufa de ar forçado a uma temperatura de $60^{\circ} \mathrm{C}$, por 48 horas. Após esse período, permaneceram por mais 24 horas em estufa comum a $60^{\circ} \mathrm{C}$, para a determinação da matéria seca.

Os dados obtidos foram ajustados através de regressão não linear, utilizando-se o método de Marquart (EUCLYDES, 1987). Para determinação da degradabilidade potencial foi utilizado o modelo proposto por ORSKOV \& McDONALD (1979), de acordo com a fórmula $\mathrm{p}=\mathrm{a}+\mathrm{b}\left(1-e^{(-\mathrm{c} x \mathrm{t})}\right)$, em que "p" é a degradabilidade potencial, "a" a fração prontamente solúvel, "b" a fração insolúvel, mas potencialmente degradável, "c" a taxa de degradação da fração "b" e " $t$ " o respectivo tempo de incubação. A degradabilidade efetiva foi calculada pela fórmula $\mathrm{p}=((\mathrm{a}+\mathrm{b} \mathrm{x} \mathrm{c}) /(\mathrm{c}$ + k)), sendo "k" a taxa de passagem.

A dieta dos animais utilizados constitui-se de forragem (Pennisetum purpureum) e concentrado (18\% de proteína bruta) na quantidade de $2 \mathrm{~kg} / \mathrm{animal} /$ dia. Os animais foram alimentados duas vezes ao dia, às 7h30min e 16h30min, quando recebiam forragem à vontade, além de $1 \mathrm{~kg} / \mathrm{animal} / \mathrm{dia}$ de concentrado.

\section{RESULTADOS E DISCUSSÃO}

Constatou-se que nas espécies Axonopus scoparius e Axonopus fissifolius, os tecidos paren- quimático (Figura 1-A, D e E) e vascular não lignificado (floema) (Figura 1-B e D) foram facilmente degradados. Tal susceptibilidade à degradação é amplamente descrita na literatura, sendo atribuída, principalmente, à natureza celulósica das paredes celulares presente nesses tecidos. De acordo com ENGELS \& SCHUURMANS (1992), as paredes primárias, por apresentarem maior concentração de celulose, são mais prontamente digeríveis. Enquanto isso, as secundárias, normalmente mais espessas e com maior grau de lignificação, são mais resistentes à degradação (Figura 1-F).

A epiderme adaxial da lâmina e da bainha foliar foi degradada em maior extensão do que a epiderme abaxial. Em ambas, foi observado que somente as paredes periclinais internas e as anticlinais foram digeridas (Figura 1- D e E). A resistência das paredes periclinais externas tem sido associada à presença de lignina, cutícula e ceras, como as principais barreiras à digestão, como já discutido por HACKER \& MINSON (1981), AKIN \& ROBINSON (1982) e WILSON (1993). Como essas estruturas também estão presentes nas espécies em questão, certamente também se constituíram em barreiras para a degradação ruminal. Observou-se, também, que a cutícula e as células epidérmicas, ligeiramente lignificadas, que se localizam sobre as nervuras permaneceram intactas. A epiderme do caule, por ser fortemente lignificada e recoberta por cutícula e ceras, não foi degradada. Essa mesma observação já foi descrita por ALVES DE BRITO et al. (1999), quando estudaram três cultivares de capim-elefante.

A bainha parenquimática do feixe vascular, característica da anatomia Kranz e, geralmente, associada à via fotossintética $\mathrm{C}_{4}$, teve baixo grau de degradação, ocorrendo apenas na parede periclinal externa de algumas células da bainha, nos feixes de pequeno porte (Figura 1-E). A resistência da bainha parenquimática à degradação se deve às paredes espessadas e lignificadas de suas células (WILSON, 1993). ALVES DE BRITO et al. (1999) observaram ligeira degradação da bainha parenquimática nos feixes de pequeno porte após 48h de incubação. A constatação de diferenças na intensidade de degradação da bainha parenquimática entre espécies e cultivares foi mencionada por AKIN \& BURDICK (1975), AKIN (1979) e MAGAI et al. (1994). Segundo AKIN (1989), a grande área ocupada e a baixa degradação da bainha parenquimática em muitas gramíneas $\mathrm{C}_{4}$, parecem ser um dos principais fatores limitantes na digestibilidade dessas forrageiras.

Ciência Rural, v. 31, n. 3, 2001. 




Figura 1 - Secções transversais das amostras submetidas à degradação ruminal por 48h. A - Área do anel esclerenquimático do caule (seta), de $\boldsymbol{A}$. scoparius cv. verde. B - Idem, com detalhe do metaxilema (seta). C - Caule de A. fissifolius $\mathrm{cv}$. verde, evidenciando o início de degradação do parênquima (seta). D - Células lignificadas do feixe vascular (seta) do Limbo de A. scoparius cv. roxo. E- Idem, ressaltando a bainha parenquimática (seta). F - Caule de A. scoparius cv. verde, apresentando células intactas com o lúmen ocupado por microrganismos (setas). P - parênquima totalmente digerido. ED - epiderme adaxial. EB - epiderme abaxial. FL floema. Barra $=100 \mu \mathrm{m}$. Itajaí (SC), 1997.

Ciência Rural, v. 31, n. 3, 2001. 
Tabela 1 - Valores calculados para os parâmetros "a", "b" e "c" oriundos da cinética de digestão ruminal da matéria seca das frações folha + caule de Axonopus, coletadas com dois períodos de crescimento. Itajaí (SC), 1997.

\begin{tabular}{|c|c|c|c|c|c|c|c|}
\hline Espécie/ cultivar & Coleta & $\mathrm{a}$ & $\mathrm{b}$ & $\mathrm{c}$ & $r^{2}$ & $\mathrm{D} e(\%)$ & $\mathrm{D} p / 48(\%)$ \\
\hline A. scoparius & $1^{\mathrm{a}}$ & 0,210 & 0,4800 & 0,0694 & 0,94 & 58,3 & 67,3 \\
\hline cv. "verde" & $2^{\underline{a}}$ & 0,237 & 0,3962 & 0,0467 & 0,95 & 51,4 & 59,1 \\
\hline A. scoparius & $1^{\mathrm{a}}$ & 0,212 & 0,4585 & 0,0496 & 0,94 & 54,0 & 62,8 \\
\hline cv. "roxo" & $2^{\mathrm{a}}$ & 0,199 & 0,4084 & 0,0574 & 0,99 & 50,2 & 58,1 \\
\hline A. fissifolius & $1^{\mathrm{a}}$ & 0,194 & 0,3695 & 0,0389 & 0.92 & 43,8 & 50,6 \\
\hline cv. "verde" & $2^{-a}$ & 0,195 & 0,4384 & 0,0279 & 0,98 & 45,1 & 51,9 \\
\hline A. fissifolius & $1^{\mathrm{a}}$ & 0,186 & 0,4036 & 0,0503 & 0,94 & 47,4 & 55,2 \\
\hline cv. "roxo" & $2^{\mathrm{a}}$ & 0,215 & 0,3394 & 0,0421 & 0,97 & 44,5 & 51,0 \\
\hline
\end{tabular}

"a" = Fração imediatamente solúvel, "b" = fração insolúvel e potencialmente degradável, "c" = taxa de degradação da fração "b". De $(\%)=$ Degradabilidade efetiva ajustada segundo o modelo $\mathrm{D} e=\mathrm{a}+((\mathrm{b} * \mathrm{c}) /(\mathrm{c}+\mathrm{k}))$, assumindo uma taxa de passagem $(\mathrm{k})=0,02($ ORSKOV \& McDONALD, 1979). D $p / 48(\%)=$ Degradabilidade potencial ajustada segundo modelo $\mathrm{D} p=\mathrm{a}+\mathrm{b}\left(1-e^{\left(-\mathrm{c}^{*} \text { tempo }\right)}\right)$, fixando o tempo em 48 horas (ORSKOV \& McDONALD, 1979).

Como já descreveram HANNA et al. (1973), AKIN et al. (1974), WILSON et al. (1983), MAGAI et al. (1994), ALVES DE BRITO et al. (1997) e ALVES DE BRITO et al. (1999), os tecidos lignificados são mais resistentes à degradação (Figura 1- A e F), sendo a lignina considerada uma barreira química para os microrganismos do rúmen. Apesar disso, AKIN et al. (1974) comentaram que o esclerênquima pode ser mais digerível do que a cutícula e o xilema (WILSON, 1993). AKIN et al. (1984) e AKIN (1989) mencionam que células esclerenquimáticas na folha são parcialmente degradadas na região periférica do tecido. Observou-se, nas células da bainha esclerenquimática do caule, uma ligeira degradação na parede periclinal externa, em amostras da primeira coleta, bem como em elementos do xilema (Figura 1B). WILSON (1993) credita ao arranjo das células no tecido e ao acesso que os microorganismos têm a elas, um impedimento à degradação maior do que a lignificação de suas paredes. Por esses motivos, tecidos como o floema, constituído por células alongadas sobrepostas que formam tubos contínuos, ou o parênquima, que possui um arranjo mais frouxo de células, são mais fáceis e primeiramente degradadas (Figura 1C). Observou-se que a maioria das células com paredes espessadas e lignificadas, quer localizadas nos feixes vasculares ou no anel esclerenquimático do caule (Figura 1-A), permaneceram intactas após $48 \mathrm{~h}$ de incubação.

Apesar de não ter sido possível mensurar as áreas de tecidos digeridos, na primeira coleta, devido à desintegração de muitas repetições após a incubação in vitro, o cultivar "verde" de $\boldsymbol{A}$. scoparius parece ser mais susceptível à degradação ruminal que o cultivar "roxo". Com o envelhecimento, não se observou diferença quanto ao grau de degradação entre os cultivares, mas uma maior resistência à digestão em todas as frações. Isso pode estar relacionado, em parte, com o aumento no espessamento das paredes celulares e à lignificação. Esse fato foi mais claramente observado nos caules, onde células do parênquima fundamental tornaram-se mais lignificadas.

Os cultivares da espécie $\boldsymbol{A}$. fissifolius apresentaram um comportamento muito similar quanto à degradação em ambas as coletas. Com o envelhecimento, constata-se resistência à degradação para ambos os cultivares, em todos as frações.

Comparativamente, entre as frações analisadas, o caule apresentou maior redução na intensidade de degradação ruminal com o envelhecimento, fato associado ao aumento na espessura das paredes celulares e à lignificação de células componentes do parênquima fundamental. Outros autores como HANNA $\boldsymbol{e t}$ al. (1973), AKIN (1979), CHERNEY \& MARTEN (1982), ALVES DE BRITO et al. (1997) e ALVES DE BRITO et al. (1999) relacionam o efeito da maturidade em caules com o aumento no teor de lignificação e a conseqüente redução da qualidade das forragens. Outros fatores ainda podem estar relacionados com a redução na qualidade das forragens. Entre esses podem-se citar a distribuição e o número de feixes vasculares. Isso implicaria menor distanciamento dos feixes, transformando-se assim em uma barreira física para o acesso dos microorganismos ruminais aos tecidos mais profundos. A natureza da lignina também pode ser associada a maior ou menor facilidade com que o sistema enzimático dos microorganismos ruminais possam degradar a parede celular dos tecidos vegetais.

A degradabilidade ruminal da matéria seca, ou das diferentes frações que compõem essa matéria, é um dos parâmetros em que a expressão da diversidade e os arranjos químicos da parede celular dos tecidos vegetais pode ser mais facilmente comprovada (DESCHAMPS, 1994).

No modelo experimental utilizado, a degradabilidade potencial representa a digestão ruminal máxima, enquanto a degradabilidade efetiva leva em consideração a taxa de passagem do alimento pelo trato gastrintestinal. Neste sentido, os resultados apresentados na tabela 1 são mais favoráveis ao cultivar "verde" de A. scoparius, em ambas as coletas e, mais expressivamente na primeira, confirmando assim, as observações descritas na análise histológica da degra-

Ciência Rural, v. 31, n. 3, 2001. 
dação dos tecidos. Quanto aos cultivares da espécie $\boldsymbol{A}$. fissifolius, tal qual na análise da degradação, apresentaram potencial de degradabilidade muito similar (Tabela 1).

A composição bromatológica, apresentada na tabela 2, permite observar que com a maturidade dos cultivares ocorreu aumento nos teores de FDA, FDN e lignina com redução nos teores de PB. Já em A. scoparius cv. "roxo", os componentes da parede celular pouco se alteraram.

A redução do teor de $\mathrm{PB}$ e o aumento das frações FDA, FDN e lignina (Tabela 2) caracterizam a perda do valor nutritivo da forragem com a maturidade, confirmando os resultados obtidos na análise da cinética da digestão (Tabela 1) e as observações histológicas da degradação dos tecidos.

Tabela 2 - Composição média (\% na matéria seca) dos materiais estudados, em termos de proteína bruta (PB) e constituintes da parede celular - fibra em detergente neutro (FDN), fibra em detergente ácido (FDA) e lignina ${ }^{11}$ Itajaí (SC), 1997.

\begin{tabular}{|c|c|c|c|c|c|}
\hline Espécie / cultivar & Coleta & $\mathrm{PB}$ & $\mathrm{FDN}^{\mathrm{la}}$ & FDA & Lignina $^{\mathrm{lb}}$ \\
\hline A. scoparius & $1^{\mathrm{a}}$ & 13,0 & 63,7 & 35,6 & 12,5 \\
\hline cv. "verde" & $2^{\mathrm{a}}$ & 6,0 & 67,5 & 42,2 & 14,7 \\
\hline A. scoparius & $1^{\mathrm{a}}$ & 11,8 & 66,4 & 41,0 & 13,4 \\
\hline cv. "roxo" & $2^{-a}$ & 5,3 & 66,3 & 40,6 & 10,7 \\
\hline A. fissifolius & $1^{\mathrm{a}}$ & 10,4 & 68,6 & 41,3 & 14,8 \\
\hline cv. "verde" & $2^{-a}$ & 6,1 & 69,5 & 42,8 & 16,0 \\
\hline A. fissifolius & $1^{-\mathrm{a}}$ & 10,1 & 66,1 & 39,3 & 12,7 \\
\hline cv. "roxo" & $2^{\mathrm{a}}$ & 6,4 & 69,7 & 44,0 & 14,0 \\
\hline
\end{tabular}

${ }^{11}$ Os desvios em relação às médias estiveram abaixo de $1,5 \%$. PB e FDA foram analisadas em duplicata usando-se a técnica do infra-vermelho (NIRS - Near Infra Red Spectroscopy).

a Amostra submetida à digestão em solução detergente neutro por 40 minutos em autoclave $\left(120^{\circ} \mathrm{C}\right)$.

b Denominada de lignina de Klason, contendo, além da lignina, alguns elementos minerais e sílica. Para essa determinação, as amostras, em triplicata, são submetidas à pré-hidrólise em ácido sulfúrico $12 \mathrm{M}$ durante 1 hora. Em seguida, o ácido é diluído para $0,4 \mathrm{M}$ e o material submetido à nova hidrólise em autoclave de bancada, por 60 minutos a $120^{\circ} \mathrm{C}$.

\section{CONCLUSÕES}

Com a maturidade, os cultivares de Axonopus scoparius apresentaram maior queda na taxa de degradabilidade efetiva, a qual foi relacionada com o espessamento da parede celular e aumento da área de tecido lignificado.

A maior área de tecidos lignificados encontrada nas frações foliares (limbo, quilha e bainha) de Axonopus fissifolius resultou em menores taxas de digestibilidade para os cultivares dessa espécie, em relação aos de Axonopus scoparius.
O cultivar "verde" de Axonopus scoparius apresentou maior suscetibilidade à degradação ruminal, quando jovem, comparado ao cultivar "roxo".

Os cultivares de Axonopus fissifolius apresentaram características similares perante a degradação ruminal.

O caule foi a fração cuja degradação decresceu em maior proporção quando comparado às frações foliares.

\section{REFERÊNCIAS BIBLIOGRÁFICAS}

AKIN, D.E. Microscopic evaluation of forage digestion by rumen microorganisms - a review. Journal of Animal Science, v.48, n.3, p.701-710, 1979.

AKIN, D.E. Histological and physical factors affecting digestibility of forages. Agronomy Journal, v.81, p.17-25, 1989.

AKIN, D.E., BROWN, R.H., RIGSBY, L.L. Digestion of stem tissues in Panicum species. Crop Science, v.24, p.769-773, 1984.

AKIN, D.E., BURDICK, D. Percentage of tissue types in tropical and temperate grass leaf blades and degradation of tissues by rumen microorganisms. Crop Science, v.15, p.661-668, 1975 .

AKIN, D.E., BURDICK, D., MICHAELS, G.E. Rumen bacterial interrelationships with plant tissue during degradation revealed by transmition electron microscopy. Applied Microbiology, v. 27 , n.6, p.1149-1156, 1974.

AKIN, D.E, ROBINSON, E.L Structure of leaves and stems of arrowleaf and crimson clovers as related to in vitro digestibility. Crop Science, v.22, p.24-29, 1982.

AKIN, D.E., ROBINSON, E.L., BARTON II, F.E., $\boldsymbol{e} \boldsymbol{t} \boldsymbol{a l}$. Changes with maturity in anatomy, histochemistry, chemistry and tissue digestibility of bermudagrass plant parts. Journal of Agricultural Food Chemistry, v.25, n.1, p.179-186, 1977.

AKIN, D.E, WILSON, J.R., WINDHAM, W.R. Site and rate of tissue digestion in leaves of $\mathrm{C}_{3}, \mathrm{C}_{4}$ and $\mathrm{C}_{3} / \mathrm{C}_{4}$ intermediate Panicum species. Crop Science, v.23, p.147-155, 1983.

ALVES DE BRITO, C.J.F., ALQUINI, Y., RODELLA, R.A., $\boldsymbol{e}$ t al. Alterações histológicas de três ecotipos de capim elefante (Pennisetum purpureum Schum.), após digestão in vitro. In: REUNIÃO ANUAL DA SOCIEDADE BRASILEIRA DE ZOOTECNIA, 34, 1997, Juiz de Fora - MG. Anais... Juiz de Fora : SBZ, 1997. v.2, p.12-14. 369p.

ALVES DE BRITO, C.J.F., RODELLA, R.A., DESCHAMPS, F.C., et al. Anatomia quantitativa e degradação in vitro de tecidos em cultivares de capim-elefante (Pennisetum purpureum Schumach.). Revista Brasileira de Zootecnia., v.28, n.2, p.223-229, 1999.

CHERNEY, J.H., MARTEN, G.C. Small grain crop forage potential: II. Interrelationships among biological, chemical, morphological and anatomical determinants of quality. Crop Science, v.22, p.240-243, 1982. 
DESCHAMPS, F.C. Degradabilidade ruminal da matéria seca e da proteína de alguns alimentos utilizáveis na alimentação de ruminantes. Revista da Sociedade Brasileira de Zootecnia, v.23, n.06, p.898-908, 1994.

ENGELS, F.M., SCHUURMANS, J.L.L. Relationship between structural development of cell walls and degradation of tissues in maize stems. Journal of Science and Food Agriculture, v.59, p.45-51, 1992.

EUCLYDES, R.F. Sistema para análises estatísticas (Guia do usuário resumido). Viçosa : Fundação Arthur Bernardes, 1987. $82 \mathrm{p}$

FELDER, N., O'BRIEN, T.P. Plant microthecnique: some principles and new methods. American Journal of Botany, v. 55, n.1, p.123-142, 1968

HACKER, J.B., MINSON, D.J. The digestibility of plant parts Herbage Abstracts, v.51, n.9, p.459-482, 1981

HANNA, W.W., MONSON, W.G., BURTON, G.W. Histological examination of fresh forage leaves after in vitro digestion. Crop Science, v.13, p.98-102, 1973.

HANNA, W.W., MONSON, W.G., BURTON, G.W. Histological and in vitro digestion study of 1- and 4 - week stems and leaves from high and low quality bermudagrass genotypes. Agronomy Journal, v.68, p.219-222, 1976.

JOHANSEN, D.A. Plant microtechnique. New York : Mc Graw Hill Book, 1940. 523p.

MAGAI, M.M., SLEPER, D.A., BEUSELINCK, P.R. Degradation of three warm-season grasses in a prepared cellulase solution. Agronomy Journal, v.86, p.1049- 1053, 1994.

NASCIMENTO JR., D. Comentários sobre métodos químicos para avaliação de forragens. Revista da Sociedade Brasileira de Zootecnia, v.3, p.233-244, 1974.

NOCEK, J.E. In situ and other methods to estimate ruminal protein and energy digestibility: a review. Journal of Dairy Science, v.71, p.2051-2069, 1988 .
ORSKOV, E.R. McDONALD, I. The estimation of protein degradability in the rumen from incubation measurements weighted according to rate of passage. Journal of Agricultural Science., v.92, p.449-453, 1979.

VENTRELLA, M.C. Anatomia quantitativa e composição bromatológica de folha e caule de três espécies de Cynodon Rich. Botucatu, 1995. 127p. Dissertação (Mestrado em Ciências Biológicas - Botânica) - Instituto de Biociências, UNESP, 1995 .

VENTRELLA, M.C., RODELLA, R.A, COSTA, C., et al Anatomia e bromatologia de espécies forrageiras de Cynodon Rich. I. Folha. In: REUNIÂO ANUAL DA SOCIEDADE BRASILEIRA DE ZOOTECNIA, 34, 1997, Juiz de Fora Anais... Juiz de Fora : SBZ, $1997^{\mathrm{a}}$ v.2, p.3-5. 369 p.

VENTRELLA, M.C., RODELlA, R.A, COSTA, C., et al. Anatomia e bromatologia de espécies forrageiras de Cynodon Rich. II. Caule. In: REUNIÃO ANUAL DA SOCIEDADE BRASILEIRA DE ZOOTECNIA, 34, 1997, Juiz de Fora. Anais... Juiz de Fora : SBZ, 1997b. v.2, p.6-8. 369 p.

WILKINS, R.J. The potential digestibility of cellulose in forages and faeces. Journal of Agricultural Science., Cambridge, v.73, p.57-64, 1969

WILKINS, R.J. The potential digestibility of cellulose in grasses and its relationship with chemical and anatomical parameters. Journal of Agricultural Science, Cambridge, v.78, p.457-464, 1972.

WILSON, J.R. Organization of forage plant tissues. In: JUNG, H.G, BUXTON, D.R., HATFIELD, R.D., RALPH, J. Forage cell wall structure and digestibility. Madison : ASA/CSSA/SSSA, 1993. p.1-32.

WILSON, J.R. Structural and anatomical traits of forages influencing their nutritive value for ruminants. In: SIMPÓSIO INTERNACIONAL SOBRE PRODUÇÃO ANIMAL EM PASTEJO, 1997, Viçosa. Anais... Viçosa : SBZ, 1997. p.171208. $472 \mathrm{p}$.

WILSON, J.R., BROWN, R.H., WINDHAM, W.R. Influence of leaf anatomy on the dry matter digestibility of $\mathrm{C}_{3}, \mathrm{C}_{4}$ and $\mathrm{C}_{3} / \mathrm{C}_{4}$ intermediate types of Panicum species. Crop Science, v.23, p.141-146, 1983.

Ciência Rural, v. 31, n. 3, 2001. 